\title{
THE INFLUENCE OF SYNTHESIS TEMPERATURE ON MANUFACTURING AND PROPERTIES OF $\mathrm{SrSi}_{2} \mathrm{O}_{2} \mathrm{~N}_{2}: \mathrm{Eu}^{2+}$ POWDERS
}

\begin{abstract}
This paper presents the results of the synthesis temperature on the properties of the ceramic powders of $\operatorname{SrSi}_{2} \mathrm{O}_{2} \mathrm{~N}_{2}: \mathrm{Eu}^{2+}$ obtained by the solid-phase reaction. Synthesis was carried out in the temperature range of $1250-1650^{\circ} \mathrm{C}$ for 2 hours in nitrogen flow in the reducing atmosphere of the graphite furnace. The phases present in the resultant powders were identified by X-ray structural analysis (XRD). Scanning electron microscopy (SEM) was used to examine the changes in the powder morphology as a result of the synthesis. The excitation and emission spectra measurements let to study phosphor photoluminescence properties. The results show the strong influence of temperature synthesis on the formation and purity of expected phases. The synthesis temperature also affects the luminescent properties of $\mathrm{SrSi}_{2} \mathrm{O}_{2} \mathrm{~N}_{2}: \mathrm{Eu}^{2+}$ ceramic powders.
\end{abstract}

Keywords: luminescence, LED, oxynitrides

\section{Introduction}

Over the years, the light sources were changing. The phosphor's discovery and their later over 100 years history of scientific research completely changed the acquisition of light. In the early $20^{\text {th }}$ century German scientist prepared diverse sort of phosphors mainly based on alkaline earth chalkogenides showing the luminescence properties. Further research contributed to fluorescent lamp introduction [1]. The fluorescent lamp with the phosphor coating application led to pre-empt the incandescent lamp, known for its relatively low luminous efficacy about $15 \mathrm{~lm} / \mathrm{W}$ and short operating life usually no longer than $1000 \mathrm{~h}$. Fluorescent lamp made from soda-lime glass tube filled with the noble gas, mercury and the phosphor coating on the inner surface of the tube demonstrate higher efficiency $80-100 \mathrm{~lm} / \mathrm{W}$ and long operating life of 10000-20000 h. The development of the calcium halophosphate phosphor $\left(\mathrm{Sb}^{3+}, \mathrm{Mn}^{2+}\right.$ activated $\mathrm{Ca}_{5}$ $\left.\left(\mathrm{PO}_{4}\right)_{3}(\mathrm{Cl}, \mathrm{F})\right)$ with blue and orange- red emission bands was the turning point in fluorescent lightning. The progress in efficiency was obtained by blending halophosphate phosphor with a red emitting phosphor ( $\mathrm{Sn}^{2+}$ activated strontium orthophosphate). The commercially available fluorescent lamp was consisted of the thriphosphor blends: $\mathrm{Eu}^{3+}$ activated $\mathrm{Y}_{2} \mathrm{O}_{3}$ (red emitting), $\mathrm{Tb}^{3+}$ -activated $\mathrm{CeMgAl}_{11} \mathrm{O}_{19}$ (green emitting) and $\mathrm{Eu}^{2+}$-activated $\mathrm{BaMgAl}_{10} \mathrm{O}_{17}$ (blue emitting) [2].

The progress in the LED technology and the invention of a blue diode quickly contributed to the discovery of white LEDs as a combination of the UV LED chip with blue, green, and red phosphors. This invention opened the way to use LED as a source of light in daily life. Presently, the most popular white LED is a mixture of an InGaN blue chip with yellow phosphor of YAG: $\mathrm{Ce}^{3+}$ [3]. This phosphor shows excellent quantum efficiency but because of a low rendering index (CRI) value and high color temperature cannot be applied as an indoor illumination [4]. This problem can be solved if YAG:Ce phosphor is replaced by nitrides and/or oxynitrides because of their excellent properties, such as chemical and thermal stability, non-toxicity and high luminescence emission and excitation with rare earth (RE) ions [5]. Lately, oxynitride phosphor with a formula of $\mathrm{MSi}_{2} \mathrm{O}_{2} \mathrm{~N}_{2}: \mathrm{Eu}^{2+}(\mathrm{M}=\mathrm{Sr}, \mathrm{Ba}, \mathrm{Ca})$ has been reported as a new perspective material for green - yellow, blue and yellow phosphors in application for white LEDs. Especially, $\mathrm{SrSi}_{2} \mathrm{O}_{2} \mathrm{~N}_{2}$ phosphor activated with $\mathrm{Eu}^{2+}$ is very interesting because of its ability to emit greenish-yellow light under UV-blue radiation [6-7]. Furthermore, the emission color of this phosphor can be controlled by increasing $\mathrm{Eu}^{2+}$ concentration [8]. Most of the up to date papers on this phosphor have focused their interest on the luminescence properties, the crystalline structure and modification of the lattice structure by other alkaline earth ions [9-11]. Manufacturing of the oxynitride phosphors was reported by using the solid state reaction in forming gas, sol-gel method or carbothermal reduction and nitridation [12].

The purpose of this study was to determine the effect of synthesis parameters on the phase composition, powders 
morphology and luminescence properties of $\mathrm{SrSi}_{2} \mathrm{O}_{2} \mathrm{~N}_{2}: \mathrm{Eu}^{2+}$ phosphor if the reaction was conducted in the flowing nitrogen in the graphite resistance furnace.

\section{Experimental}

$\mathrm{SrSi}_{2} \mathrm{O}_{2} \mathrm{~N}_{2}: \mathrm{Eu}^{2+}(4 \%)$ was prepared by a solid-state reaction of commercial, high purity powders. A mixture of $\mathrm{Si}_{3} \mathrm{~N}_{4}$ (UBE, 98\%), $\mathrm{SiO}_{2}$ (Merck, 99\%), $\mathrm{SrCO}_{3}$ (Abcr, 99.99\%), $\mathrm{Eu}_{2} \mathrm{O}_{3}$ (Treibacher, $99.99 \%$ ) was homogenized in an agate mortar with addition of acetone and then powders were dried in $80^{\circ} \mathrm{C}$. The ratio between $\mathrm{Si}_{3} \mathrm{~N}_{4}$ and $\mathrm{SiO}_{2}$ was 1.8:0.2. Synthesis was con- ducted in a graphite furnace (Thermal Technology) in a nitrogen flow in the reducing atmosphere (nitrogen, purity 99.999\%). All samples were hold for 2 hours at various temperature $\left(1250-1650^{\circ} \mathrm{C}\right)$. Heating rate was $10^{\circ} \mathrm{C} / \mathrm{min}$. After synthesis, powders were pulverised in an agate mortar. The morphology of powders was studied by Scanning Electron Microscope (SEM) HITACHI S-3400N which registered secondary electrons image (SE). The photoluminescence properties and phase composition were measured in Institute of Experimental Physic at the University of Gdansk. Phase composition of the resultant samples was identified using powder X-ray diffraction method (Bruker, D2PHASER) with $\mathrm{Cu} \mathrm{K} \mathrm{K}_{\alpha 1}=1.54 \AA$. Samples were measured in the $2 \mathrm{Q}$ range from $10^{\circ}$ to $65^{\circ}$. The spectra of emission were
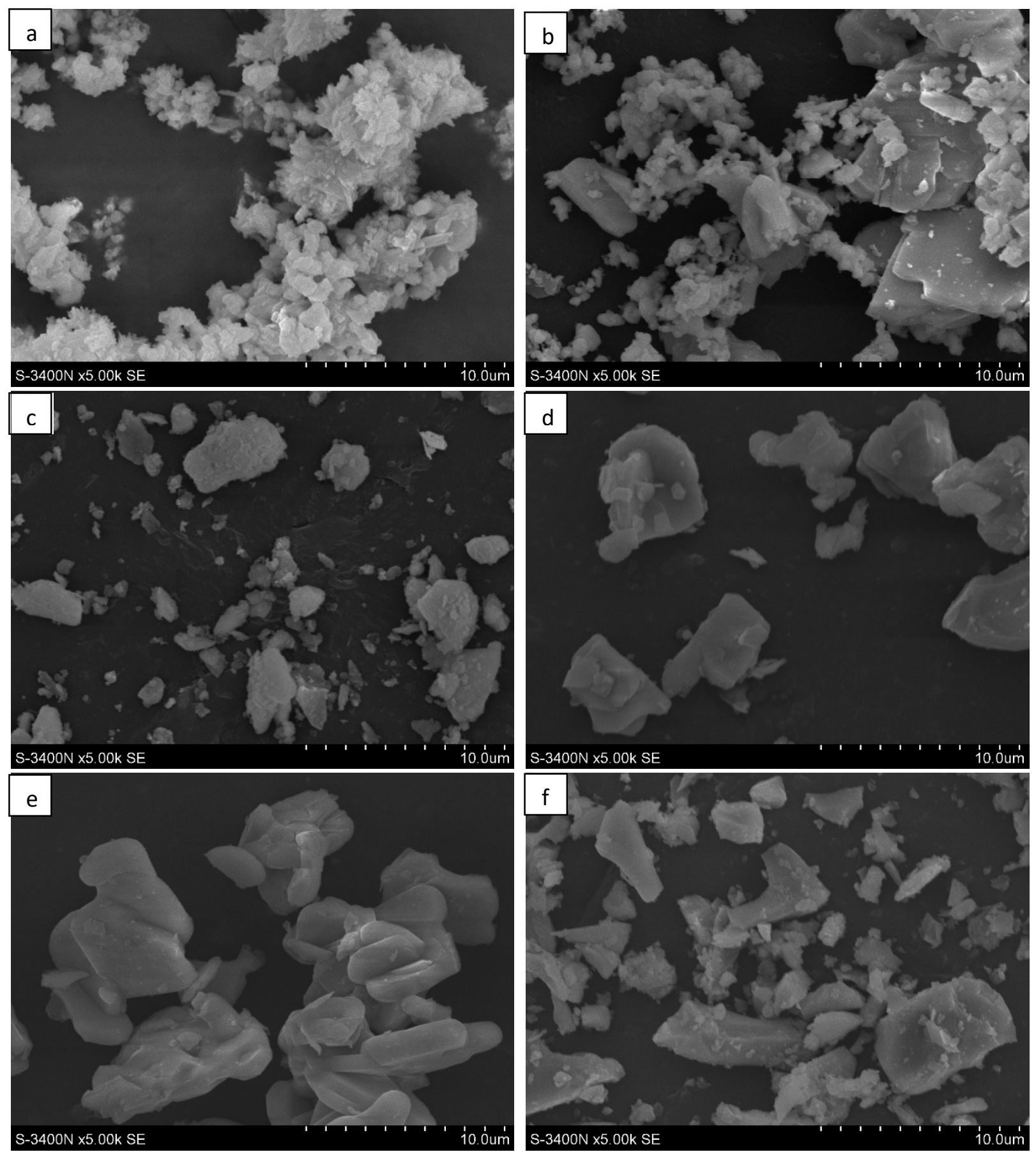

Fig. 1. Morphology of phosphor powders obtained at various temperature $\left(\mathrm{a}-1250, \mathrm{~b}-1350, \mathrm{c}-1400, \mathrm{~d}-1450, \mathrm{e}-1550, \mathrm{f}-1650^{\circ} \mathrm{C}\right), \mathrm{SEM}$ 
measured by Horiba FluoroMax-4P spectrofluorometer equipped with a 150W Xe arc lamp and R928P photomultiplier. All measurements were performed at room temperature.

\section{Results and discussion}

Figure 1 shows the morphology of $\mathrm{SrSi}_{2} \mathrm{O}_{2} \mathrm{~N}_{2}: \mathrm{Eu}^{2+}$ powder after synthesis at different temperature. A strong impact of synthesis temperature on powder particle morphology is clearly visible. After synthesis at lower temperature $\left(1250-1350^{\circ} \mathrm{C}\right)$ powder particles are fine, their size is close to the size of the initial materials. If synthesis was conducted at higher temperature $\left(1400^{\circ} \mathrm{C}\right)$ then particles form larger aggregates (Fig. 1c) with average size of 1-5 $\mu \mathrm{m}$. The most significant difference in particles morphology can be observed after synthesis at $1450-1550^{\circ} \mathrm{C}$ temperature since large particles with rounded edges are noticeable. Fragile and sharp edged small particles apart from the large ones were observed after synthesis at the highest temperature $\left(1650^{\circ} \mathrm{C}\right)$. The morphology of particles after annealing at temperature over $1400^{\circ} \mathrm{C}$ may indicate the presence of glassy phase.

The XRD patterns of $\mathrm{SrSi}_{2} \mathrm{O}_{2} \mathrm{~N}_{2}: \mathrm{Eu}^{2+}$ obtained at various temperature are shown in Figure 2. The reference diffraction pattern of $\mathrm{Sr}_{1.02} \mathrm{Si}_{2} \mathrm{O}_{2} \mathrm{~N}_{2}$ (ICDD 01-076-3141) is placed at the bottom of the picture. The temperature increase influenced the main phase crystallization. In all tested samples the expected triclinic $\mathrm{Sr}_{1.02} \mathrm{Si}_{2} \mathrm{O}_{2} \mathrm{~N}_{2}$ phase (ICDD 01-076-3141) was detected and for samples synthesized in the temperature range of $1400-1550^{\circ} \mathrm{C}$ this triclinic phase was the main phase. The pure triclinic phase, was obtained for samples synthesised at $1450^{\circ} \mathrm{C}$ and $1500^{\circ} \mathrm{C}$. If synthesis was carried out at lower temperature $\left(1250,1350^{\circ} \mathrm{C}\right)$ then the unreacted phase of $\mathrm{Si}_{3} \mathrm{~N}_{4}$ (marked on Fig. 2 as *) and $\mathrm{Sr}_{2} \mathrm{SiO}_{4}$ (\#) were observed. Silica with strontium oxide form a low melting eutectic (at $1358^{\circ} \mathrm{C}$ ) and this phenomenon can cause formation of the liquid phase at higher temperature. Presence of the liquid phase may support crystallization of triclinic $\mathrm{Sr}_{1.02} \mathrm{Si}_{2} \mathrm{O}_{2} \mathrm{~N}_{2}$ phases as it was shown previously [13]. The samples synthesized at $1650^{\circ} \mathrm{C}$ showed decomposition of triclinic $\mathrm{Sr}_{1.02} \mathrm{Si}_{2} \mathrm{O}_{2} \mathrm{~N}_{2}$ and formation of the unknown phase accompanied by a significant amount of amorphous phase. The remaining peaks were not unequivocally identified in a view of a large number of potential phases. Details of the investigated samples are collected in Table 1.

Figure $3 \mathrm{a}$ and $3 \mathrm{~b}$ presents emission spectra of the selected phosphor samples obtained at $1250-1550^{\circ} \mathrm{C}$ under $\lambda=350 \mathrm{~nm}$ excitation. The spectra consist of single emission bands in the

TABLE 1

Quantitative phase composition

\begin{tabular}{|c|c|c|c|c|c|c|}
\hline \multirow{2}{*}{ Pattern [PDF] } & \multirow{2}{*}{ Compound name } & \multirow{2}{*}{$\begin{array}{l}\text { Chemical } \\
\text { Formula }\end{array}$} & \multicolumn{4}{|c|}{ Quantity[\%] } \\
\hline & & & $1250\left[{ }^{\circ} \mathrm{C}\right]$ & $1350\left[{ }^{\circ} \mathrm{C}\right]$ & $1400\left[{ }^{\circ} \mathrm{C}\right]$ & $1450\left[{ }^{\circ} \mathrm{C}\right]$ \\
\hline 01-076-3141 & Strontium Silicon Oxide Nitride & $\mathrm{Sr}_{1.02} \mathrm{Si}_{2} \mathrm{O}_{2} \mathrm{~N}_{2}$ & 48.40 & 78.42 & 94.90 & 100.00 \\
\hline $\begin{array}{l}00-039-1256 \\
00-038-0271\end{array}$ & Strontium Silicate & $\mathrm{Sr}_{2} \mathrm{Si} \mathrm{O}_{4}$ & $\begin{array}{l}23.66 \\
13.09\end{array}$ & $\begin{array}{l}9.44 \\
6.68\end{array}$ & $\begin{array}{l}5.10 \\
-\end{array}$ & - \\
\hline $01-071-6479$ & Silicon Nitride & $\mathrm{Si}_{3} \mathrm{~N}_{4}$ & 14.85 & 5.46 & - & - \\
\hline
\end{tabular}

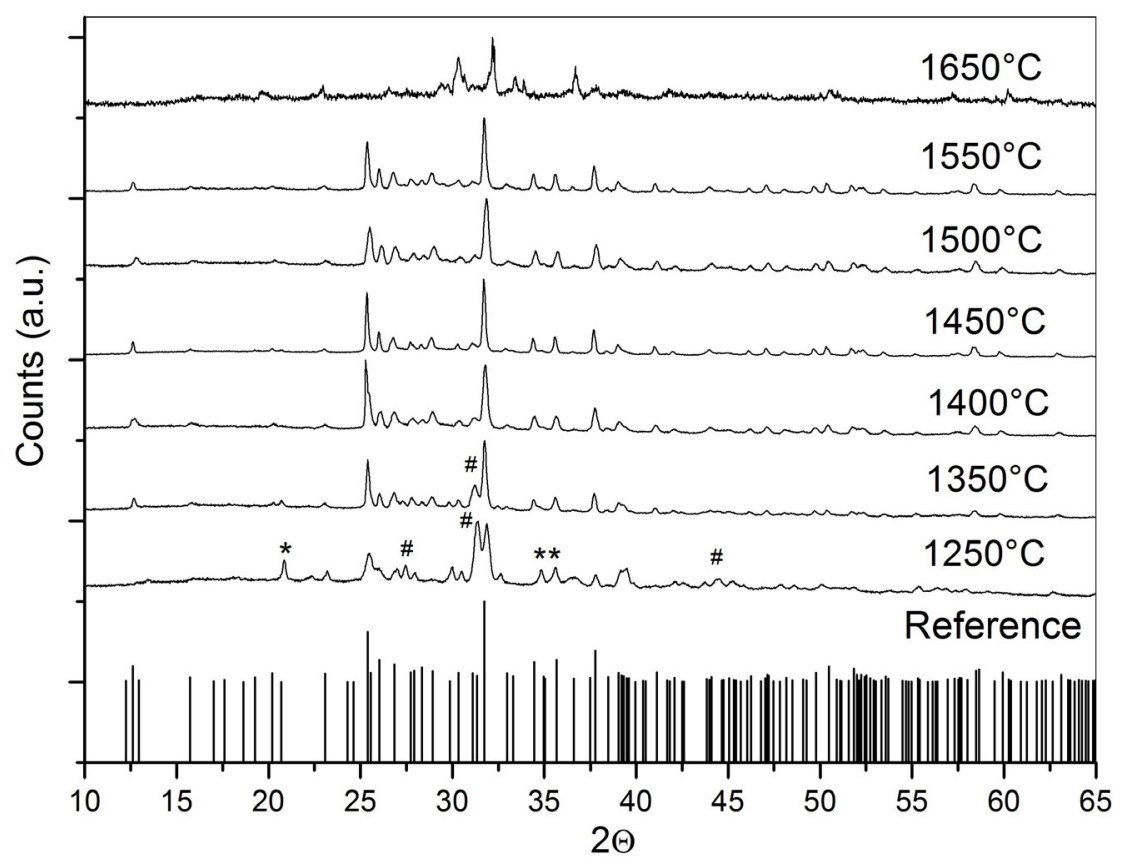

Fig. 2. XRD pattern of phosphor powder prepared at various temperature. $\mathrm{Si}_{3} \mathrm{~N}_{4}$ (ICDD 01-071-6479) marked as * and $\mathrm{Sr}_{2} \mathrm{SiO}_{4}$ (ICDD 00-0391256 and 00-038-0271) marked as \#. The reference pattern of $\mathrm{Sr}_{1.02} \mathrm{Si}_{2} \mathrm{O}_{2} \mathrm{~N}_{2}$ (ICDD 01-076-3141) is given at the bottom of the picture 

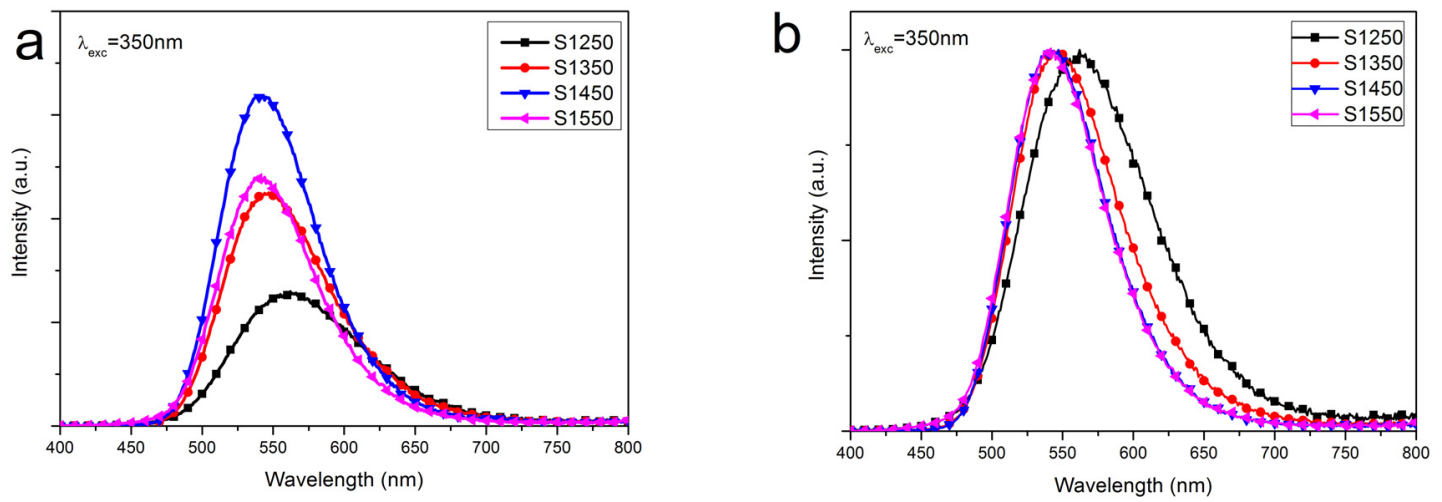

Fig. 3. Emission spectra (a) and normalized emission spectra (b) of $\mathrm{SrSi}_{2} \mathrm{O}_{2} \mathrm{~N}_{2}: \mathrm{Eu}^{2+}$ synthesized at $1250-1550^{\circ} \mathrm{C}$

range of 460-700 $\mathrm{nm}$, peaking at 540-550 $\mathrm{nm}$ that can be ascribed to the $4 \mathrm{f}^{6} 5 \mathrm{~d} \rightarrow 4 \mathrm{f}^{7}$ transition of the $\mathrm{Eu}^{2+}$ ions. In Figure $3 \mathrm{a}$ the relative emission intensity of each sample was preserved, while in Fig $3 b$ the spectra were normalized.

Figure 3a shows influence of synthesis temperature on emission intensity of the phosphor. The luminescence intensity rises with synthesis temperature, reaching maximum for the specimen obtained at $1450^{\circ} \mathrm{C}$. Above this temperature emission intensity was lower. Figure $3 \mathrm{~b}$ shows that the peak wavelength of the emission band shifts when the synthesis temperature increases from 1250 to $1450^{\circ} \mathrm{C}$, which is accompanied by the narrowing of the emission band. Comparing those spectra with $\mathrm{XRD}$ results it is possible to consider the influence of secondary phases on the emission spectrum in both phosphors: the considerable amount of strontium silicate in $1250^{\circ} \mathrm{C}$ specimen results in broader and shifted emission spectrum while the emission band is narrower for the specimen with dominating strontium oxynitride in specimens derived at temperature over $1350^{\circ} \mathrm{C}$. Samples prepared at the temperature range of $1450-1550^{\circ} \mathrm{C}$ show the same position of emission peaks. Decrease of emission intensity at $1550^{\circ} \mathrm{C}$ is related to the total decomposition of $\mathrm{SrSi}_{2} \mathrm{O}_{2} \mathrm{~N}_{2}$ (Fig. 2) and migration of $\mathrm{Eu}^{2+}$ to the non-identified compound or to the amorphous phase. The same position of the emission peak as in the $\mathrm{SrSi}_{2} \mathrm{O}_{2} \mathrm{~N}_{2}$ (Fig. 3b) indicates the same coordination environment of $\mathrm{Eu}^{2+}$ ion in the new compound or in amorphous phase.

\section{Conclusions}

Green emitting phosphor with a designed formula of $\mathrm{Eu}_{0.04} \mathrm{Sr}_{0.96} \mathrm{Si}_{2} \mathrm{O}_{2} \mathrm{~N}_{2}$ has been synthesized by the solid state reaction in various temperature range. The particle morphology and photoluminescence intensity were largely dependent on the synthesis temperature and the resultant phase composition. Synthesis carried out at temperature of $1400-1450^{\circ} \mathrm{C}$ facilitated manufacturing the phosphor powder of high-purity. Unreacted silicon nitride was observed after synthesis below $1400^{\circ} \mathrm{C}$ and it negatively affected emission of specimens. The highest emission intensity was obtained after synthesis at $1450^{\circ} \mathrm{C}$. Synthesis at temperature at $1550^{\circ} \mathrm{C}$ led to reduction of emission intensity as a results of decomposition of triclinic strontium oxynitride main phase to amorphous and unidentified phases was observed at $1650^{\circ} \mathrm{C}$.

\section{Acknowledgements}

The financial support by NCN (2011/01/B/ST8/07480) and NCBR (PBS3/ A5/48/2015) is gratefully acknowledged.

\section{REFERENCES}

[1] S. Shionoya, W.M. Yen, H. Yamamoto, Phosphor Handbook, CRC Press, (2006).

[2] A.M. Srivastava, T.J. Sommerer, The Electrochemical Society Interface 7, 28-31 (1998).

[3] D. Michalik, M. Sopicka-Lizer, J. Plewa, T. Pawlik, Archives of Metallurgy and Materials 56, 1257-1264 (2011).

[4] Y.H. Song, W.J. Park, D.H. Yoon, Journal of Physics and Chemistry of Solids 71, 143-147 (2010).

[5] R. Fu, S. Agathopoulos, X. Song, X. Zhao, H. He, X. Yu, Optical Materials 33, 99-102 (2010).

[6] X. Li, R. Zhang, R. Cui, C. Deng, Journal of Alloys and Compounds 650, 470-474 (2015).

[7] O. Ermakova, W. Paszkowicz, A. Kaminska, J. Barzowska, K. Szczodrowski, M. Grinberg, R. Minikayev, M. Nowakowska, S. Carlson, G. Li, Ru-Shi Liu, A. Suchocki, The Journal of Chemical Physics 141 (2014).

[8] Y.H. Song, W.J. Park, D.H. Yoon, Journal of Physics and Chemistry of Solids 71, 473-475 (2010).

[9] Z. Xia, S. Miao, M. Chen, M.S. Molokeev, Q. Liu, Inorganic Chemistry 54, 7684-7691 (2015).

[10] X. Songa, R. Fua, S. Agathopoulos, H. Hea, X. Zhaoa, J. Zenga, Materials Science and Engineering B 164, 12-15 (2009).

[11] Y. Gu, Q. Zhang, Y.Li, H. Wang, R.J. Xie, Materials Letters 63, 1448-1450 (2009).

[12] R.J. Xie, N. Hirosaki, Y. Li, T. Takeda, Luminescence and Applications Materials 3, 3777-3793 (2010).

[13] T. Pawlik, D. Michalik, J. Barzowska, K. Szczodrowski, K. Zieliński, N. Górecka, Materiały Ceramiczne 67, 143-148 (2015). 